work with L. F. de Beaufort on "The Fishes of the Indo-Australian Archipelago" published in three volumes between 1911 and 1916. But to biologists in general, Max Weber is probably better known for his able leadership of the Dutch Siboga Expedition in 1899-1900. This expedition covered a distance of about 12,000 sea miles in the different basins of the East Indian Archipelago, and was equipped with the best oceanographical apparatus of the time. The reports of the Siboga Expedition edited by Max Weber form one of the major contributions to the science of oceanography, and have filled a large gap in our knowledge of the fauna of that region. Weber himself undertook the study of the fishes collected by the Siboga Expedition and published in 1913 his great volume, in which no less than 131 new species were described and 240 species recorded for the first time in the Indo-Australian Archipelago. This work he dedicated to his wife, Mme. Dr. A. A. Weber-van Bosse, who accompanied him on his travels and is herself a botanist of great distinction. Prof. Weber is also the author of the most comprehensive textbook on the Mammalia to be found in any language. The first edition of this work, "Die Säugetiere", was published in 1904 in one volume; the second and latest edition, in two volumes, appeared in 1928. Taking a general view of the work, it is the most complete account in existence of the taxonomy and structure of mammals, living and fossil.

\section{Prof. Moriz Benedikt}

Prof. Moriz Benedikt, a leading Austrian neurologist, was born at Eisenstadt in Hungary on July 6, 1835 . His medical education was carried on in Vienna, where he studied under Hyrtl, Brücke, Skoda, Oppolzer, Rokitansky and other well-known teachers, and qualified in 1859. During the period 1861-75 he was chiefly concerned with electrotherapy and neuropathology. Afterwards he turned his attention to a comparative anatomical investigation of the brain in man and animals, and craniometric and psychological studies. In 1899 he was appointed professor of neurology in the Vienna medical faculty. In addition to a large number of articles on neuropathology, most of which were published in the Wiener medizinische Presse between 1869 and 1882, he wrote on anthropology, ophthalmology and otology. Like his contemporary, Charcot, he took a keen interest in art, and a few days before his death, which took place on April 14, 1920, at the age of eighty-five years, published an essay on Raphael. His name has been attached, at Charcot's suggestion, to a syndrome characterised by oculomotor paralysis on one side with paresis and tremor of the upper extremity on the other.

\section{Electrical Units and the I.E.C.}

THE practical system of units now in use is consistent, in the sense that the product of a resistance in ohms and a current in amperes gives a potential difference in volts; but it suffers from the defect that the units themselves are not those which would most naturally be derived from the fundamental mechanica] units. As a consequence, the product of current in amperes and potential difference in volts gives the power, not in the usual mechanical unit (ergs per second), but in joules per second, that is, in watts. A degree of simplicity is maintained by making the relation between the practical and the absolute unit an integral power of ten in each case. We understand that the International Electrotechnical Commission at its meetings last month adopted the proposals of Prof. G. Giorgi (discussed in NATuRE of April 21, 1934 , p. 597) to regard these units as derived, not from the centimetre-gram-second system, but from a metre-kilogram-second system. In this system, the unit of velocity is the metre per second, so that the kinetic energy of unit mass (1 kgm.) moving with unit velocity would be $1000 \times 100^{2}$, that is, $10^{7}$ times that of a gram moving with a velocity of $1 \mathrm{~cm}$. a second. Thus the unit of mechanical energy on this system is $10^{7}$ ergs $=1$ joule, just as in the practical electrical system.

IT is clearly not sufficient to arrange that the product of current and E.M.F. shall give power in watts, but if a further relation is imposed, then the whole system-ohm, volt, ampere, farad, coulomb, henry, joule, watt and weber-becomes definite, and the powers of ten by which these units are related to their c.G.s. counterparts need not burden the memory; they can be recovered at any time by a simple argument. For the additional relation required, Prof. Giorgi assigns the value unity to the present international ohm, and thus makes all the units on his system identical with those of the practical system. An argument in favour of this particular choice, rather than that of current or voltage, for example, is that dimensional formulæ are appreciably simplified if resistance is taken as the fourth independent magnitude, in addition to length, mass and time. The Commission has at the same time endorsed the resolution passed at Oslo in 1930 , to the effect that $\mu_{0}$, the permeability of empty space, should be retained in magnetic formulæ as a physical quantity and not as a mere numeric differing from unity. On the other hand, authors are left free to use the rationalised or unrationalised formulæ, according as the value which they choose to assign to the permeability of a vacuum does or does not absorb the constant $4 \pi$.

\section{Archæological Discovery in Crete}

A DIScovery in Crete, of which the intrinsic interest is enhanced by the recent publication of the concluding volumes of Sir Arthur Evans's "Palace of Minos", in which he deals with the Minoan script, is announced from Athens. A dispatch from the correspondent of The Times, which appears in the issue of June 28, states that Dr. Marinatos, director of the museum at Candia, has announced that among antiquities discovered in the Arkalokori district is a copper double axe on which is a three line inscription in characters not previously known in the Minoan civilisation, but bearing some resemblance to those on the famous Phaistos disc. The antiquities with which this inscribed axe was found are dated at about 